\title{
Promoting Treatment Adherence Through Motivational Interviewing
}

\author{
Ana M. Bisonó \\ Jennifer Knapp Manuel
}

Alyssa A. Forcehimes

$\mathrm{n}$ medical settings, patient adherence is one of

the greatest challenges to achieving treatment goals. According to Zweben and Zuckoff (2002), treatment adherence describes "the extent to which people follow through with agreed-on or prescribed actions, or do what providers expect them to do, where treatment is concerned" (p. 300). Motivational interviewing (MI) can be used to increase a variety of treatment compliant behavior, such as attending scheduled appointments and medication compliance (Zweben \& Zuckoff, 2002). DiMatteo, Giordani, and Lepper (2002) conducted a meta-analysis to examine the relationship between patient adherence and medical treatment outcomes in 63 studies over a 30 -year period. Results showed that on average $26 \%$ more patients had a better treatment outcome when adherence rates were high. The correlation was even stronger in studies that did not involve medications (e.g., behavior change interventions) and when the illness was chronic (e.g., hypertension, hypercholesterolemia, intestinal disease, and sleep apnea). Their review supports the simple yet important fact that treatment efficacy often depends on patient adherence. Given the strong correlation between treatment adherence and positive outcomes, what can practitioners do to increase patient adherence? 


\section{Importance of Motivational Interviewing in Increasing Adherence to Treatment}

MI is a collaborative method that elicits from patients their own motivation or reasons for changing their behavior. Practitioners then reinforce patient reasons for change through the use of reflective listening. It can be thought of as a way of speaking so others hear and hearing when others speak. MI is a client-centered, directive style of counseling introduced by Miller (1983) for use in addressing substance abuse. Since then, this counseling style has been applied to areas beyond addictions, and over 70 clinical trials have established MI as an efficacious method for facilitating behavior change as well as increasing adherence to treatment. This method is intended for use particularly when patient motivation and adherence are important for treatment to be effective. Given that motivation is often a significant obstacle in behavior change, MI is particularly useful in dealing with many health problems related to lifestyle as well as in the prevention and treatment of many chronic illnesses (Miller, 2004).

Efforts to enhance motivation have received increasing attention in health care settings (Emmons \& Rollnick, 2001). Findings have supported the efficacy of MI to increase retention in substance abuse treatment, smoking cessation treatment, HIV-risk prevention, diet, and exercise, as well as medication adherence. MI has been incorporated in health behavior interventions as a way of enhancing motivation for behavior change (Emmons \& Rollnick, 2001). A number of clinical trials have found that adding even one session of MI at the early stages of treatment can improve the efficacy by increasing patient retention and adherence, thus improving outcomes (Miller, 2000).

Although there are many strategies that can be used in the application of this method, MI is not a technique so much as a style for practitioner-patient communication. The underlying spirit of MI is the key in carrying out this style of counseling in a meaningful way. This chapter offers a method to practitioners interested in increasing patient treatment adherence, which has shown promising positive results. The emphasis is to explain the spirit of MI and provide an overview of the techniques and skills used in its application.

\section{Theoretical Basis of Motivational Interviewing}

MI has been described as a client-centered counseling style used for eliciting behavior change by helping patients to explore and resolve ambivalence (Miller \& Rollnick, 1991; Rollnick \& Miller, 1995). Miller (2004) further described it as "a way of being with people, that is also directive in seeking to move the person toward change by selectively evoking and strengthening the patient's own reasons for change" (p. 4). To use this method, the practitioner and the patient work together to address the patient's health care needs, emphasizing a "side-by-side companionable approach" (Miller, 2004, p. 4).

According to Miller (2004), the approach fits with a few established models of psychotherapy. In particular, MI suits Carl Rogers' client-centered (1980) approach to psychotherapy and Daryl Bem's self-perception theory (1967). Rogers' approach (1980) highlights the spirit of MI, the way of being with another in an empathic and genuine manner. Bem's self-perception theory (1967) has parallels with the mechanisms of change in MI, emphasizing the process of change that occurs as individuals voice their opinions aloud.

In MI, the practitioner selectively elicits and reinforces (through reflective listening) positive self-statements, consequently directing the patient to move in a positive direction. However, the patient, not the practitioner, argues for change. Thus, MI is a patient-centered yet directive counseling style that seeks to explore and 
resolve the patient's ambivalence by eliciting and augmenting particular reasons for the patient's change in behavior.

\section{The Spirit of Motivational Interviewing}

The spirit of MI is based on three fundamental components: collaboration, evocation, and autonomy. MI is a collaborative approach, meaning that the practitioner does not assume an authoritarian or expert role in the relationship. Instead, the practitioner respects the patient's perspective and autonomy. In addition, the practitioner fosters a warm, comfortable environment in which the patient is able to communicate honestly and openly with the practitioner.

The second fundamental element of the spirit of MI is evocation. MI's evocative nature assumes that practitioners can draw out perspective and values from their patients. MI emphasizes that perspectives and values should be elicited from the patient rather than imparted. Instead of considering the patient's mind as an empty vessel ready to be filled with facts and feedback, the practitioner explores the patient's own intrinsic values to facilitate change. Two Latin verbs regarding education, docere and ducere, highlight the important difference between evoking and imparting information. Docere means to lead or impart knowledge or information, whereas ducere means to draw forth or evoke from within. The words express a subtle but important distinction of what MI is and is not. The spirit of MI focuses on ducere - the ability to draw forth rather than an emphasis on pulling the patient toward the goal (Miller, 2004; Miller \& Rollnick, 2002).

The third fundamental element within the spirit of MI is autonomy. In MI, the practitioner understands that it is up to the patient to decide whether or not he or she wants to change, and how best to go about that change. The practitioner respects the patient's choices and decisions regarding self-direction, even if they are divergent from what the practitioner thinks best for the patient.

\section{Principles of Motivational Interviewing}

MI is based on four key principles that are consistent with the general spirit described above. This section provides a brief overview of these principles (see Table 5.1).

1. Express empathy: Expressing empathy involves actively listening to the patient and conveying an understanding of the patient's perspective, without judging, criticizing, or blaming. In MI, ambivalence about change is regarded as normal and a part of the change process; therefore empathic listening is used to understand and accurately reflect this ambivalence (Miller \& Rollnick, 1991, 2002).

2. Develop discrepancy: A goal in $\mathrm{MI}$ is for patients to see a discrepancy between their personal goals and their present behavior. The objective is for the practitioner to direct the discussion in such a way that the patients perceive this discrepancy and the reasons to change their behavior without pressure from the practitioner. Eliciting reasons for change from the patient is more powerful than giving the patient prescribed reasons why change is necessary (Miller \& Rollnick, 1991, 2002).

3. Roll with resistance: Avoiding pushing against resistance to change is a third MI principle. Rather than arguing with a patient who is resistant to change, practitioners roll with this resistance. Arguing in favor of a certain position with the patient-for instance, arguing to persuade patients to take medications-will likely result in defensiveness on his or her 
part, a decreased desire to take the medication, and lower medication compliance. Practitioners can roll with resistance by reflecting or rephrasing the patient's arguments against change. They can also try to increase the patient's participation in problem solving so that the patient is generating solutions rather than refuting solutions offered by the practitioner. Patient resistance may also be a signal that the practitioner should modify his or her approach with the patient or accept more realistic outcome goals (Miller \& Rollnick, 1991, 2002).

4. Support self-efficacy: Self-efficacy, a person's confidence in his or her ability to achieve a specific goal, is an important predictor of a successful treatment outcome. If a practitioner believes that the patient is able to change his or her behavior and expresses this support, the patient may feel empowered by the idea that change is possible. An objective in MI is to increase patients' confidence in their ability to change and support steps taken to change (Miller \& Rollnick, 1991, 2002).

\section{General Methods of Motivational Interviewing}

A primary goal in MI is to shape the language that patients use to describe their dilemmas. "Change talk" occurs when clients give their own reasons and arguments for a behavioral change (Miller \& Rollnick, 1991, 2002) and it generally falls into one of four categories: desire, ability, reasons, and need. Key words that are indicative of the desire change talk category are want, wish, and prefer. The ability change talk category refers to patient statements of self-confidence, such as able, can, and could. The reasons change talk category includes patient arguments for change, such as why the patient should change or benefits to changing. Utterances that fall into the need change talk category include words such as need to, have to, and important. See Table 5.2 for examples of change talk. The four change talk categories predict patient commitment to change, which in turn predicts behavioral change by the patient (Amrhein, Miller, Yahne, Palmer, \& Fulcher, 2003). When a patient offers a practitioner change talk, for example, "I sure would save a lot of money if I quit buying cigarettes," the practitioner then has the opportunity to reflect this change talk and thus reiterate the patient's own arguments for change. Reflections allow the patient to hear his or her change talk, which further reinforces what the patient has said (Miller, 2004).

Skills used in MI to elicit change talk from patients include the following: (1) asking open questions, (2) affirming, (3) listening reflectively, and (4) summarizing. These skills are often referred to by the acronym OARS (open questions, affirming, reflecting, and summarizing).

1. Ask open questions: Asking open questions, questions that cannot be answered with a simple "Yes" or "No," gives the patient the opportunity to elaborate and focus on what he or she feels is important. An open question allows a patient to give his or her own perspective without reacting to cues from the practitioner. Additionally, questions of this kind set the stage for a discussion in which the patient, rather than the practitioner, does most of the talking. Although it is also normal to ask closed questions (questions that elicit a "Yes"/"No" or short response), about half of all questions should be open ones. Examples of open questions include the following:

"What brings you here today?"

"If you decided you wanted to exercise more, how would you go about that?"

"You mentioned that your weight has caused you a lot of problems. Tell me what that is like." 
Table 5.1 Description of Motivational Interviewing (MI) Principles

\begin{tabular}{ll}
\hline MI Principle & Brief Description \\
\hline $\begin{array}{l}\text { Express empathy } \\
\text { Develop discrepancy }\end{array}$ & $\begin{array}{l}\text { Actively listen to the patient and understand his or her perspective } \\
\text { Develop a discrepancy between the patient's goals and current behavior } \\
\text { Ratient should give reasons or arguments for change }\end{array}$ \\
Roll with resistance & $\begin{array}{l}\text { Reflect resistance from the patient } \\
\text { Arguing with the patient for change is counterproductive }\end{array}$ \\
Support self-efficacy & $\begin{array}{l}\text { Enhance the patient's confidence to change } \\
\text { The patient should initiate change in behavior and the practitioner should } \\
\text { support the patient's ability to initiate change }\end{array}$
\end{tabular}

Table $\mathbf{5 . 2}$ Examples of Change Talk

\begin{tabular}{ll}
\hline Change Talk Category & Example of Change Talk \\
\hline Desire & "I really want to quit smoking." \\
Ability & "I know that I can remember to take my medication every day." \\
Reasons & "Smoking is killing me. I can't breathe, I'm always out of breath, \\
Need & and it's expensive." \\
\hline
\end{tabular}

2. Affirm: Affirmations are an important part of a practitioner-patient discussion. Affirmations can be direct compliments or appreciative statements. Practitioners can also affirm patients through reflective listening and statements that convey an understanding of the patient. Affirmations increase collaboration between the patient and practitioner and facilitate patient exploration (Miller \& Rollnick, 2002). Often simple affirmations are used, such as letting the patients know you appreciate their openness or complimenting them when they make good choices:

"Thanks for coming in today."

“That's a great idea."

"This situation seems to be very difficult but you are handling it well."
3. Listen reflectively: Reflective listening is one of the most important, yet difficult, skills in MI. Reflective listening occurs when a practitioner makes a statement that is a guess at what the client has said. Ideally, reflections will move the session forward and shape the patient's speech in the direction of change. It is not imperative, or even desirable, that reflections relay the patient's exact idea. An incorrect reflection still conveys that the practitioner is listening to the patient and is trying to understand his or her perspective. Some reflective statements are similar to questions, except that there is a difference in inflection. Whereas in questions voice tone turns up at the end, in reflections the inflection is down at the end of a statement. The difference between inflections 
can have substantial meaning in MI. For instance, if a practitioner reflects, "It is important to you to stay healthy," the practitioner is conveying that he or she understands what the patient is saying and is reflecting the patient's value of good health. However, if the practitioner said, "Is it important to you to stay healthy?" the practitioner is asking a question rather than communicating an understanding of the patient's perspective.

There are two main types of reflections: simple and complex reflections. Simple reflections simply repeat or rephrase what the patient has said, whereas complex reflections tend to continue the paragraph, meaning the practitioner anticipates the patient's train of thought. Although simple reflections repeat the patient's statements, the practitioner is still guiding the session by choosing what to reflect. Reiterating the patient's speech also reinforces what the client has said, especially if patient change talk is being repeated:

(a) Patient: "My wife wants me to stop smoking. She is always nagging me about it."

Practitioner: "Your wife is really concerned about you and wants to help you."

(b) Patient: "I want to lose weight; I just hate eating healthy foods. Why can't nutritious food taste good!"

Practitioner: "It's frustrating to you how healthy food tastes, yet losing weight is really important to you."

4. Summarize: The fourth OARS skill used in $\mathrm{MI}$ is summarizing. Summary statements are used to tie patients' statements together and communicate that the practitioner has been listening to the patient and understands his or her perspective. Summaries are also used to reinforce important material that has been discussed in consultation between a practitioner and a patient. Summaries can be used to collect ideas, link together ideas, or as a transition, indicating a shift in the direction of the discussion or to wrap up a consultation.

\section{Importance and Confidence Rulers}

Although an understanding of the theory and principles of MI is necessary to effectively use a number of MI skills, others "may not require skillfulness in the overall method or even in understanding of the underlying theory to be used effectively in practice" (Miller, 2004, p. 5). For example, importance rulers are a widely used and relatively easy way to assess a patient's confidence, ambivalence, and readiness to change. This technique can be used to assess the importance of certain behaviors such as losing weight, quitting smoking, and reducing drinking. When using this ruler with a patient, the practitioner asks, "On a scale of zero to ten, where zero is not at all important and ten is very important, how important is it for you to quit smoking?" This question is then followed with a "backward" question that will elicit change talk from the patient. For example, if a patient responds with a five, then the practitioner would ask, "Why are you a five and not a zero?" This type of "backward" follow-up question sets up the patient to respond with change talk, rather than resistance. Asking why the patient is not at a higher number, would have the opposite and undesired effect of causing the patient to defend the status quo (Miller, 2004).

Confidence rulers are similar to importance rulers, except that they assess the patient's belief in his or her ability to change. For example, practitioners may ask, "On a scale from zero to ten, where zero is not at all confident and ten is extremely confident, how confident are you that you could quit smoking?" Practitioners can then ask why the patient did not choose a lower number. An additional follow-up question might be 
"What would it take for you to go from a four to a six?" (Miller \& Rollnick, 2002).

After the patient answers the practitioner's "backward question," the practitioner can follow up with an open question such as, "What else?" This type of question is intended to elicit further change talk from the patient. By listening reflectively and empathically to the patient, the practitioner will likely elicit reasons and argument to change from the patient. Following open questions, the practitioner may summarize the patient's statements, thus reinforcing his or her responses (Miller, 2004).

\section{Brief Case Example}

This example is a compilation of real interactions between practitioners and patients and exemplifies how quickly a practitioner can elicit change talk from a patient. This case example is illustrative of the empathic and supportive characteristics of MI. During this 2-min example, the practitioner guided the patient from being concerned about his smoking but unsure of how to quit, to listing all the reasons he should quit smoking, and discussing treatment options with his practitioner.

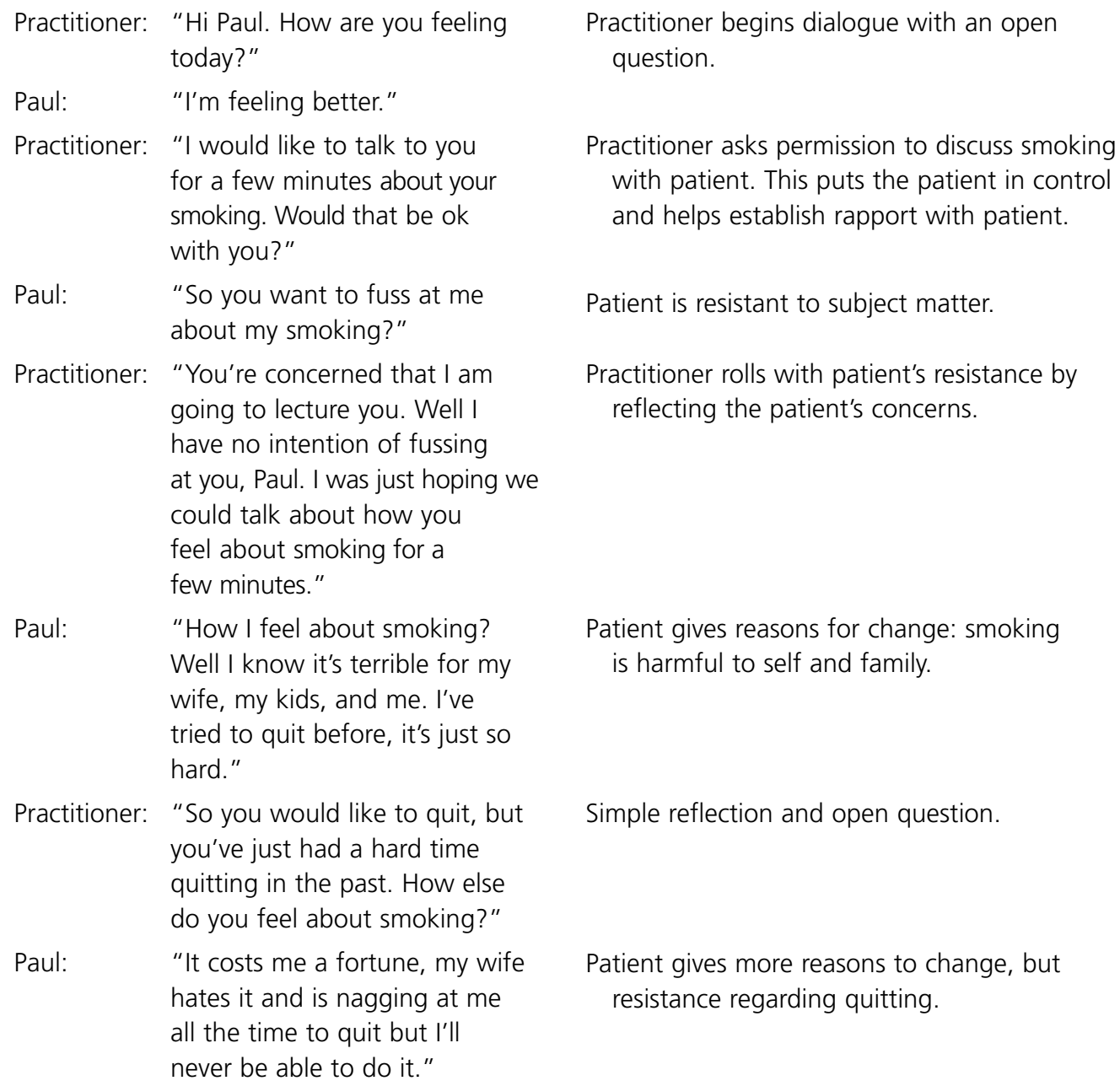

Practitioner begins dialogue with an open question.

Practitioner asks permission to discuss smoking with patient. This puts the patient in control and helps establish rapport with patient.

Patient is resistant to subject matter.

Practitioner rolls with patient's resistance by reflecting the patient's concerns.

Patient gives reasons for change: smoking is harmful to self and family.

Simple reflection and open question.

Patient gives more reasons to change, but resistance regarding quitting. 
(Continued)

\begin{tabular}{|c|c|c|}
\hline Practitioner: & $\begin{array}{l}\text { "So although you would really like to } \\
\text { quit smoking, it's too hard so there's } \\
\text { really no point in trying." }\end{array}$ & $\begin{array}{l}\text { Practitioner gives an amplified reflection- } \\
\text { an exaggeration of what the } \\
\text { patient said. }\end{array}$ \\
\hline Paul: & $\begin{array}{l}\text { "Well I wouldn't say there's no point. } \\
\text { I mean I think I could quit if I really tried." }\end{array}$ & $\begin{array}{l}\text { Patient gives more change talk. } \\
\text { Reflection. }\end{array}$ \\
\hline Practitioner: & $\begin{array}{l}\text { "So you're pretty sure you could quit } \\
\text { smoking. How ready do you feel to quit?" }\end{array}$ & $\begin{array}{l}\text { Practitioner assesses the patient's } \\
\text { readiness to change. }\end{array}$ \\
\hline Paul: & "Well I want to quit, I'm just not sure how." & Change talk. \\
\hline Practitioner: & $\begin{array}{l}\text { "Well I know of some treatments that } \\
\text { have helped a lot of people quit smoking. } \\
\text { Would you be interested in hearing about } \\
\text { them?" }\end{array}$ & $\begin{array}{l}\text { Practitioner asks permission to give the } \\
\text { patient information regarding } \\
\text { quitting smoking. }\end{array}$ \\
\hline Paul: & "OK." & $\begin{array}{l}\text { Emphasizes patient's control. Patient is } \\
\text { the expert and knows what will work } \\
\text { best for him. }\end{array}$ \\
\hline Practitioner: & $\begin{array}{l}\text { "You have a few different options and } \\
\text { it's really up to you. You can choose } \\
\text { whatever feels most comfortable to you } \\
\text { or you can decide that none of these } \\
\text { options are for you. You are the one who } \\
\text { needs to decide what is best for you." }\end{array}$ & \\
\hline
\end{tabular}

\section{Review of Empirical Evidence for the Effectiveness of Motivational Interviewing in Treatment Adherence Studies}

As MI has expanded to populations other than substance abuse, numerous studies have been conducted to evaluate its effectiveness for a wide range of clinical problems. MI and adaptations of MI (AMIs) were first developed to promote change in alcohol and drug problems. One example of an AMI is to give the patient personalized feedback based on results from standardized measures, such as a serum chemistry panel. The feedback from the lab tests is given in an MI style, which includes processes such as reflective listening. The discussion between the practitioner and patient then incorporates the essential methods of MI, including open-ended questions, affirmations, reflective listening, and summaries (this process is described later in the chapter). The term $A M I$ is used to refer to interventions that preserve
MI principles as a central part of treatment. Often, however, it is difficult to assess if these studies of AMIs are actually preserving the principles of MI, because fidelity of MI has seldom been documented (Burke, Arkowitz, \& Dunn, 2002).

Recent studies have examined the role that MI plays in increasing treatment adherence, and the results have been generally positive. In a randomized pilot study, Smith, Heckemeyer, Kratt, and Mason (1997) studied whether treatment adherence and glucose control could be improved in a group of older obese women with noninsulin dependent diabetes mellitus (NIDDM) by adding MI strategies to a behavioral intervention for obese patients. Participants were randomly assigned to one of the two treatment modalities: to a standard 16-week behavioral group focusing on weight control or the same behavioral group plus three individual MI sessions. Participants in the MI group were significantly better than the standard group in the number of meetings attended (13.3 vs. 8.9), food diaries completed 
(15.2 vs. 10.1), and blood glucose records kept (46.0 vs. 32.2 days). These results support the rationale for including an MI component to standard behavioral treatment programs.

Kemp, Kirov, Everitt, Hayward, and David (1998) conducted a randomized clinical trial comparing outcomes of treatment adherence in a group of patients diagnosed with psychiatric disorders. In this study, compliance therapy, a blend of MI and cognitive approaches to treating psychotic symptoms, was compared with treatment as usual. The results showed a significant effect for the compliance therapy treatment group post-treatment on measures of treatment compliance (19\%), insight (18.8\%), and drug attitudes (15.6\%).

In a pilot study, Daley, Salloum, Zuckoff, Kirisci, and Thase (1998) studied the efficacy of an MI-based motivational therapy on treatment adherence and completion for patients dually diagnosed with depression and cocaine dependence. Participants were assigned to either motivational therapy or treatment as usual upon discharge from an inpatient psychiatric unit. Results from comparison between patients in the two conditions showed that the use of motivational therapy increased treatment adherence and completion rates in this population. Patients in the motivational therapy group were significantly more likely to complete outpatient treatment, attend more treatment sessions, and experience fewer rehospitalizations than the patients in the treatment as usual group. The researchers concluded that the findings from this pilot support motivational therapy to increase treatment adherence and completion in patients with depression and cocaine dependence.

Swanson, Pantalon, and Cohen (1999) conducted a randomized trial to study the effectiveness of MI on treatment adherence. Participants were psychiatric inpatients, the majority of whom were also diagnosed with substance abuse/dependence disorders. Treatment conditions included treatment-as-usual (which included prescription therapy, individual and group therapy, activities planning, milieu treatment, and planning for after discharge) and treatment-as-usual plus MI
(MI component consisted of brief feedback on the results of an MI-based assessment administered early in the hospitalization period and a one-hour motivational interview, using MI techniques, before discharge). Results illustrate that patients in the treatment-as-usual plus MI group were significantly more likely to attend the first outpatient appointment after discharge (47\%) than the patients in the treatment-as-usual group. Based on these results, the authors concluded that brief MI-based interventions promote treatment adherence among psychiatric and dually diagnosed individuals.

In another study, Berg-Smith et al. (1999) used an MI-based intervention to increase treatment adherence and retention of adolescents in the "Dietary Intervention Study in Children." The participants were part of a multicenter clinical trial that implemented a family-based group approach aimed at lowering dietary fat to decrease levels of cholesterol in high-risk children. The MI-based intervention appeared to be an ageappropriate shift from a family-based intervention, and the adolescents in the study were satisfied with the approach.

In the area of exercise, Young, King, Sheehan, and Stefanick (2002) evaluated the association among baseline stage of motivation readiness for exercise and adherence to a 9-month exercise intervention. Results showed that although most of the men and about a third of women in the study reached the goals of the intervention, the stage of motivational readiness for exercise did not predict adherence to the intervention.

Dilorio, Resnicow, McDonnell, Soet, McCarty, and Yeager (2003) conducted a pilot study using an MI-based intervention to increase treatment adherence to antiretroviral medications. Patients were randomly assigned to either motivational enhancement therapy (MET) or a control group. Results indicated that although differences in missed medications were not significant between the two groups, patients in the MET condition reported that they were more likely to follow the prescription regimen as recommended by their health practitioner. 


\section{Who Might Benefit from Motivational Interviewing?}

Numerous studies have examined the efficacy of MI using a wide range of populations. Studies support MI across several behavioral domains, including decreasing drinking, drug use, smoking and risky behaviors, and increasing exercise and fruit and vegetable intake (Belcher et al., 1998; Berg-Smith et al., 1999; Burke, Arkowitz, \& Menchola, 2003; Butler et al., 1999; Carey et al., 1997, 2000; Colby et al., 1998; DiMatteo et al., 2002; Dunn, Deroo, \& Rivara, 2001; Ershoff et al., 1999; Glasgow, Whitlock, Eakin, Lichtenstein, 2000; Harland et al., 1999; Kemp et al., 1998; Noonan \& Moyers, 1997; Resnicow et al., 2001; Schubiner, Herrold, \& Hurt, 1998; Smith et al., 1997; Valanis et al., 2001; Woollard et al. 1995; Young et al., 2002). These findings suggest that $\mathrm{MI}$ is applicable in a wide range of settings across diverse populations. In addition, MI may be particularly efficacious with individuals who are angry, resistant to treatment, and less ready for change (Heather, Rollnick, Bell, \& Richmond, 1996; Project MATCH Research Group, 1997, 1998; Rollnick \& Heather, 1992).

\section{Contraindications of Motivational Interviewing}

Despite MI's success in numerous studies across diverse populations, there are instances in which the use of MI is not suggested. For instance, MI may not be the ideal approach with patients who are already very ready to make a behavioral change (www.motivationalinterview.org; Project MATCH Research Group, 1997, 1998). Although empathic listening and a respect for the patient's autonomy are key components of MI, patients who are ready and willing to make a behavioral change may not want or need to talk about their ambivalence or confidence in changing. Although some techniques are unnecessary with eager and motivated patients, MI skills remain helpful as a way to interact with a patient and encourage continued success. In addition, Miller and Rollnick (2002) state that there are certain situations in which using MI creates ethical dilemmas. It is not appropriate for MI to be used when a practitioner has a personal investment in the patient's decision or the relationship is coercive in nature (Miller \& Rollnick, 2002).

\section{Obstacles to Using Motivational Interviewing in Health Care Settings}

\section{Time}

Health care practitioners may feel overwhelmed, knowing the average patient contact is 10 to $15 \mathrm{~min}$ and is often restricted to one visit with a particular patient (Emmons \& Rollnick, 2001). Although time constraints may seem to be an obstacle for using MI in health care settings, MI has been shown to be an efficacious treatment to enhance patient retention, medical adherence, treatment adherence, and outcomes by incorporating even a single session of MI into active treatment (Miller, 2004). Brief AMIs that honor the spirit of MI are very useful and can be applied even in a short period of time (Miller, 2004).

\section{Expert Role}

The MI approach can be significantly different from traditional treatment provided in settings where individuals seek help for health behavior change (Emmons \& Rollnick, 2001). Practitioners who follow the "expert-driven, practitioner-centered" model commonly used in medical settings can find it challenging to embrace the collaborative spirit of MI (Resnicow et al., 2002). Traditional counseling approaches place the practitioner in the "expert" role, leaving the patient in the position of complying with or ignoring the advice the "expert" offers. Instead, one of the central goals of MI is to put the patient in the role of the "expert," allowing the individual to interpret the information that is 
exchanged, and to decide whether or not this information is applicable to his or her current situation (Emmons \& Rollnick, 2001). In this model, the patient does much of the mental work associated with his or her treatment (Resnicow et al., 2002). This is particularly useful in health care settings, in which patients may be ambivalent about changing their behaviors. The brevity of MI interventions facilitates patient and practitioner exploration of ambivalence regarding behavior change.

This is a difficult shift in roles, as the practitioner has expert knowledge of the results of particular behaviors. When met with ambivalence, practitioners are tempted to exclaim, "Can't you see that you must stop drinking-It's destroying your liver!” Although many doctors give advice to their patients and educate them on the reasons they should change their behaviors, patients often meet this advice and information with resistance and defensiveness. MI allows patients to explore their ambivalence about changing (Rollnick \& Heather, 1992) and initiate movement toward change. According to Rollnick, Mason, and Butler (1999), some of the behavioral changes that practitioners and patients discuss include diet alterations, adjusting meal times, drinking less alcohol or abstaining from alcohol, exercising more, quitting smoking, taking or changing medications, monitoring glucose levels, abstaining from drugs, or increasing their liquid intake.

Some suggestions to avoid the expert role:

- Avoid arguing for change while the patient argues against it.

- Don't assume you have to come up with all the solutions for health behavior change.

- Avoid labeling the patient.

- Be careful not to assume that your patients ought to change, want to change, or that your patients' health is the prime motivating factor for them to change.

- Don't assume that if your patient decides not to change, the consultation has failed (Rollnick et al., 1999)

\section{Mastery}

Mastering the application of MI skills while honoring its spirit requires some practice. Some practitioners choose to attend MI training workshops and dedicate time to develop their skill level, but many do not have the time or desire to acquire a high level of MI expertise. For this reason, brief techniques that preserve the spirit of MI have been developed (Miller, 2004). An example of such technique is the "importance and confidence rulers" described earlier, which can be easily learned and applied. As previously mentioned, MI is a "way of being" with people, rather than a "step-by-step" approach, which allows the practitioner to use its techniques and to continue to improve his or her skill level.

\section{Discussion}

MI has emerged as a promising approach that facilitates internally motivated change, and increases treatment adherence in a variety of areas (i.e., diet, exercise, smoking cessation, and substance use reduction) and multiple settings (i.e., inpatient, outpatient and community clinics). However, as in all other approaches, MI is not a "fix all" that works in every area or for everyone.

Some caution in the interpretation of these results is warranted. In many of the trials conducted, the description of how MI and AMIs were implemented in the study protocol is missing, leaving the reader wondering what methods were actually used. Therefore, it is difficult to assess whether MI has worked in a given trial when it is not clear that MI was in fact used. Rollnick \& Miller (1995) caution that care should be taken to only call "Motivational Interviewing" the approaches that honor and carry through the spirit of MI. Furthermore, treatment adherence is not measured consistently across studies. In many of these trials, adherence is assessed through patients' self-reports, treatment attendance, or outcomes (e.g., attributing weight loss to treatment adherence when factors other than "adherence" are the main contributing factors). Treatment adherence is not defined consistently across trials. 
Nevertheless, MI is a well-established effective treatment method in the area of substance abuse, and research is illuminating its benefits in other domains. The use of MI in other areas is rather recent and therefore more research, correcting the above-mentioned problems, is needed. Why MI works as well as it does remains a puzzle that requires further investigation. Many trials of MI in multiple areas are underway and the results will continue to shed light on its effectiveness.

\section{Suggested Readings}

Emmons, K. M., \& Rollnick, S. (2001). Motivational interviewing in health care settings. American Journal of Preventive Medicine, 20(1), 68-74.

Miller, W. R., \& Rollnick, S. (1991). Motivational interviewing: Preparing people to change addictive behaviors. New York: Guilford Press.

Miller, W. R., \& Rollnick, S. (2002). Motivational interviewing: Preparing people for change (2nd ed.). New York: Guilford Press.

Resnicow, K., Dilorio, C., Soet, J. E., Borrelli, B., Hecht, J., \& Ernst, D. (2002). Motivational interviewing in health promotion: It sounds like something is changing. Health Psychology, 21(5), 444- 451 .

Rollnick, S., \& Heather, N. (1992). Negotiating behavior change in medical settings: The development of brief motivational interviewing. Journal of Mental Health, 1(1), 25-38.

Rollnick, S., Mason, P., \& Butler, C. (1999). Health behavior change: A guide for practitioners. New York: Churchill Livingstone.

\section{References}

Amrhein, P. C., Miller, W. R., Yahne, C. E., Palmer, M., Fulcher, L. (2003). Client commitment language during motivational interviewing predicts drug use outcomes. Journal of Consulting and Clinical Psychology, 71(5), 862-879.

Belcher, L., Kalichman, S., Topping, M., Smith, S., Emshoff, J., Norris, F., et al. (1998). A randomized trial of a brief HIV risk reduction counseling intervention for women. Journal of Consulting and Clinical Psychology, 66(5), 856-861.

Bem, D. (196). Self-perception: An alternative interpretation of cognitive dissonance phenomena. Psychological Review, 74(3), 183-200.

Berg-Smith, S. M., Stevens, V. J., Brown, K. M., Van Horn, L., Gernhofer, N., Peters, E., et al. (1999). A brief motivational intervention to improve dietary adherence in adolescents. Health Education Research, 14(3), 399-410.

Burke, B., Arkowitz, H., \& Dunn, C. (2002). The efficacy of motivational interviewing and its adaptations: What we know so far. In W. R. Miller \& S. Rollnick (Eds.), Motivational interviewing: Preparing people for change (2nd ed.). New York: Guilford Press.

Burke, B., Arkowitz, H., \& Menchola, M. (2003). The efficacy of motivational interviewing: A meta-analysis of controlled clinical trials. Journal of Consulting and Clinical Psychology, 71(5), 843-861.

Butler, C. C., Rollnick, S., Cohen, D., Bachmann, M., Russell, I., \& Stott, N. (1999). Motivational consulting versus brief advice for smokers in general practice: A randomized trial. British Journal of General Practice, 49, 611-616.

Carey, M. P., Braaten, L. S., Maisto, S. A., Gleason, J. R., Forsyth, A. D., Durant, L. E., et al. (2000). Using information, motivational enhancement, and skills training to reduce the risk of HIV infection for low-income urban women: A second randomized clinical trial. Health Psychology, 19(1), 3-11.

Carey, M. P., Maisto, S. A., Kalichman, S. C., Forsyth, A. D., Wright, E. M., \& Johnson, B. T. (1997). Enhancing motivation to reduce the risk of HIV infection for economically disadvantaged urban women. Journal of Consulting and Clinical Psychology, 65(4), 531-541.

Colby, S. M., Monti, P. M., Barnett, N. P., Rohsenow, D. J., Weissman, K., Spirito, A., et al. (1998). Brief motivational interviewing in a hospital setting for adolescent smoking: A preliminary study. Journal of Consulting and Clinical Psychology, 66(3), 574-578.

Daley, D. C., Salloum, I. M., Zuckoff, A., Kirisci, L., \& Thase, M. E. (1998). Increasing treatment adherence among outpatients with depression and cocaine dependence: Results of a pilot study. American Journal of Psychiatry, 155(11), 1611-1613. 
Dilorio, C., Resnicow, K., McDonnell, M., Soet, J., McCarty, F., \& Yeager, K. (2003). Using motivational interviewing to promote adherence to antiretroviral medications: A pilot study. Journal of the Association of Nurses in AIDS Care, 14(2), 52-62.

DiMatteo, M. R., Giordani, P. J., \& Lepper, H. S. (2002). Patient adherence and medical treatment outcomes: A meta-analysis. Medical Care, 40(9), 794-811.

Dunn, C., Deroo, L., \& Rivara, F. P. (2001). The use of brief interventions adapted from motivational interviewing across behavioral domains: A systematic review. Addiction, 96, 1725-1742.

Emmons, K. M., \& Rollnick, A. (2001). Motivational interviewing in health care settings: Opportunities and limitations. American Journal of Preventive Medicine, 20(1), 68-74.

Ershoff, D. H., Quinn, V. P., Boyd, N. R., Stern, J., Gregory, M., \& Wirtshafter, D. (1999). The Kaiser Permanente prenatal smoking-cessation trial: When more isn't better, what is enough? American Journal of Preventive Medicine, 17(3), 161-168.

Glasgow, R., Whitlock, E., Eakin, E., \& Lichtenstein, E. (2000). A brief smoking cessation intervention for women in low-income planned parenthood clinics. American Journal of Public Health, 90(5), 786-789.

Harland, J., White, M., Drinkwater, C., Chinn, D., Farr, L., \& Howel, D. (1999). The Newcastle exercise project: A randomized controlled trial of methods to promote physical activity in primary care. Behavioral Medicine Journal, 319, 828-832.

Heather, N., Rollnick, S., Bell, A., \& Richmond, R. (1996). Effects of brief counselling among male heavy drinkers identified on general hospital wards. Drug and Alcohol Review, 15, 29-38.

Kemp, R., Kirov, G., Everitt, B., Hayward, P., \& David, A. (1998). Randomised controlled trial of compliance therapy. British Journal of Psychiatry, 172, 413-419.

Miller, W. R. (1983). Motivational interviewing with problem drinkers. Behavioural Psychotherapy, 11, 147-172.

Miller, W. R. (2000). Rediscovering fire: Small interventions, large effects. Psychology of Addictive Behaviors, 14(1), 6-18.

Miller, W. R. (2004). Motivational interviewing in service to health promotion. The art of health promotion: Practical information to make programs more effective. American Journal of Health Promotion, 18(3), 1-10.
Miller, W. R., \& Rollnick, S. (1991). Motivational interviewing: Preparing people to change addictive behaviors. New York: Guilford Press.

Miller, W. R., \& Rollnick, S. (2002). Motivational interviewing: Preparing people for change (2nd ed.). New York: Guilford Press.

Noonan, W. C., \& Moyers, T. B. (1997). Motivational interviewing. Journal of Substance Misuse, 2, 8-16.

Project MATCH Research Group. (1997). Project MATCH secondary a priori hypotheses. Addiction, 92, 1671-1698.

Project MATCH Research Group. (1998). Matching alcoholism treatments to client heterogeneity: Project MATCH three-year drinking outcomes. Alcoholism: Clinical and Experimental Research, 22, 1300-1311.

Resnicow, K., Dilorio, C., Soet, J. E., Borrelli, B., Hecht, J., \& Ernst, D. (2002). Motivational interviewing in health promotion: It sounds like something is changing. Health Psychology, 21(5), 444-451.

Resnicow, K., Jackson, A., Wang, T., De, A. K., McCarty, F., Dudley, W. N., et al. (2001). A motivational interviewing intervention to increase fruit and vegetable intake through black churches: Results of the eat for life trial. American Journal of Public Health, 91(10), 1686-1693.

Rogers, C. (1980). A way of being. Boston: Houghton Mifflin.

Rollnick, S., \& Heather, N. (1992). Negotiating behavior change in medical settings: The development of brief motivational interviewing. Journal of Mental Health, 1(1), 25-38.

Rollnick, S., Mason, P., \& Butler, C. (1999). Health behavior change: A guide for practitioners. New York: Churchill Livingstone.

Rollnick, S., \& Miller, W. R. (1995). What is motivational interviewing? Behavioral and Cognitive Psychotherapy, 23, 325-334.

Schubiner, H., Herrold, A., \& Hurt, R. (1998). Tobacco cessation and youth: The feasibility of brief office interventions for adolescents. Preventive Medicine, 17, A47-A54.

Smith, D. E., Heckemeyer, C. M., Kratt, P. P., \& Mason, D. A. (1997). Motivational interviewing to improve adherence to a behavioral weight-control program for older obese women with NIDDM: A pilot study. Diabetes Care, 20(1), 52-54.

Swanson, A. J., Pantalon, M. V., \& Cohen, K. R. (1999). Motivational interviewing and treatment adherence 
among psychiatric and dually diagnosed patients. Journal of Nervous and Mental Disease, 187(10), 630-635.

Valanis, B., Lichtenstein, E., Mullooly, J., Labuhn P., Broody, K., Severson, H. H., et al. (2001). Maternal smoking cessation and relapse prevention during health care visits. American Journal of Preventive Medicine, 20(1), 1-8.

Woollard, J., Beilin, L., Lord, T., Puddey, I., MacAdam, D., \& Rouse, I. (1995). A controlled trial of nurse counselling on lifestyle change for hypertensives treated in general practice: Preliminary results.
Clinical and Experimental Pharmacology and Physiology, 22, 466-468.

Young, D. R., King, A. C., Sheehan, M., \& Stefanick, M. L. (2002). Stage of motivational readiness: Predictive ability for exercise behavior. American Journal of Health Behavior, 26(5), 331-341.

Zweben, A., \& Zuckoff, A. (2002). Motivational interviewing and treatment adherence. In W. R. Miller \& S. Rollnick (Eds.), Motivational interviewing: Preparing people for change (2nd ed.). New York: Guilford Press. 